\title{
Ethylene-Insensitive Tobacco Shows Differentially Altered Susceptibility to Different Pathogens
}

\author{
Bart P. J. Geraats, Peter A. H. M. Bakker, Christopher B. Lawrence, \\ Enow A. Achuo, Monica Höfte, and L. C. van Loon
}

\begin{abstract}
First, second, and sixth authors: Graduate School Experimental Plant Sciences, Faculty of Biology, Section Phytopathology, Utrecht University, P.O. Box 800.84, 3508 TB Utrecht, The Netherlands; third author: Department of Bioagricultural Science \& Pest Management, Colorado State University, Fort Collins; and fourth and fifth authors: Laboratory of Phytopathology, Faculty of Agricultural and Applied Biological Sciences, Ghent University, Coupure Links 653, B-9000 Ghent, Belgium.
\end{abstract}

Current address of B. P. J. Geraats: Nunhems Zaden BV, P.O. Box 4005, 6080 AA Haelen, Holland.

Accepted for publication 5 February 2003.

\begin{abstract}
Geraats, B. P. J., Bakker, P. A. H. M., Lawrence, C. B., Achuo, E. A., Höfte, M., and van Loon, L. C. 2003. Ethylene-insensitive tobacco shows differentially altered susceptibility to different pathogens. Phytopathology 93:813-821.

Transgenic tobacco plants (Tetr) expressing the mutant etrl-1 gene from Arabidopsis thaliana are insensitive to ethylene and develop symptoms of wilting and stem rot when grown in nonautoclaved soil. Several isolates of Fusarium, Thielaviopsis, and Pythium were recovered from stems of diseased Tetr plants. Inoculation with each of these isolates of 6-week-old plants growing in autoclaved soil caused disease in Tetr plants but not in nontransformed plants. Also, when 2-week-old seedlings were used, nontransformed tobacco appeared nonsusceptible to the Fusarium isolates, whereas Tetr seedlings did develop disease. Tetr seedlings were not susceptible to several nonhost Fusarium isolates. In contrast to results with Fusarium isolates, inoculation of 2-week-old seedlings with a Thielaviopsis isolate resulted in equal symptom develop-

tial range of pathogens to which Tetr tobacco plants display enhanced susceptibility, the pathogenicity of several root and leaf pathogens was tested. Tetr plants were more susceptible to the necrotrophic fungi Botrytis cinerea and Cercospora nicotianae and the bacterium Erwinia carotovora, but only marginally more to the bacterium Ralstonia solanacearum. In contrast, the biotrophic fungus Oidium neolycopersici, the oomycete Peronospora tabacina, and Tobacco mosaic virus caused similar or less severe symptoms on Tetr plants than on nontransformed plants. Total peroxidase activity of Tetr plants was lower than that of nontransformed plants, suggesting a role for peroxidases in resistance against necrotrophic microorganisms. A comparable range of pathogens was examined on Arabidopsis and its ethylene-insensitive mutants etrl-1 and ein2-1. With the exception of one Fusarium isolate, ethylene insensitivity increased susceptibility of Arabidopsis plants to a similar spectrum of necrotizing pathogens as in tobacco. Thus, both ethylene-insensitive tobacco and Arabidopsis plants appear to be impaired in their resistance to necrotrophic pathogens.
\end{abstract} ment of nontransformed and Tetr tobacco. In order to explore the poten-
The plant hormone ethylene is a simple hydrocarbon that regulates many diverse metabolic and developmental processes. Ethylene is involved in seed germination, influences plant growth, stimulates senescence of plant organs, and induces ripening of fruits. In addition, ethylene is functional during biotic and abiotic stresses such as extreme temperatures, drought, wounding, and infection by different pathogens $(1,5)$.

The role of ethylene in plant-pathogen interactions is complex. Ethylene can induce resistance and ethylene perception is often required for basal resistance, but the production of ethylene on infection can aggravate symptom development. Treatment with ethylene induced biochemical defense reactions in various plants (6) and ethylene pretreatment of tomato increased resistance to the fungus Botrytis cinerea (9). However, exogenously applied ethylene was shown to stimulate gray mold, caused by $B$. cinerea, on tomato, pepper, cucumber, bean, rose, and carnation (6). Similarly, increased ethylene levels stimulate lesion expansion after infection of $N N$ tobacco leaves with Tobacco mosaic virus (TMV) (21). Moreover, ethylene-insensitive ein2-1 mutants of Arabidopsis

Corresponding author: B. P. J. Geraats; E-mail address: b.geraats@nunhems.com

*The $e$-Xtra logo stands for "electronic extra" and indicates that the online version contains supplemental material not included in the print edition. Figure 5 is in color online.

Publication no. P-2003-0428-01R

(c) 2003 The American Phytopathological Society showed reduced disease severity after inoculation with the bacterial leaf pathogens Pseudomonas syringae or Xanthomonas campestris (3). The ethylene-insensitive never-ripe mutant of tomato displayed fewer symptoms after inoculation with Pseudomonas syringae, $X$. campestris, or the fungal root pathogen Fusarium oxysporum (27), but similar symptoms after infection with $B$. cinerea (9). Soybean mutants with reduced sensitivity to ethylene were less susceptible to Pseudomonas syringae and the oomycete Phytophthora sojae (16).

Besides reducing disease severity, ethylene insensitivity can also enhance disease severity. For example, Arabidopsis mutant ein2-1 showed enhanced susceptibility to $B$. cinerea (38), the bacterium Erwinia carotovora (31), and several Pythium spp. (13). In apparent conflict with results of Bent et al. (3), ein2-1 was also demonstrated to be more susceptible to Pseudomonas syringae and $X$. campestris (40). Mutants of soybean with reduced sensitivity to ethylene showed enhanced susceptibility to the fungal pathogens Septoria glycines and Rhizoctonia solani (16). These examples indicate that the effect of altered ethylene perception on disease severity depends on the host-pathogen interaction.

In addition, resistance of Arabidopsis to the necrotrophic pathogens B. cinerea (38), Erwinia carotovora (31), and Pythium spp. (13) is dependent on jasmonate (JA) signaling. In contrast, resistance to the biotrophic oomycete Peronospora parasitica does not depend on ethylene or JA signaling, but requires salicylic acid (SA) signaling $(37,38)$. Likewise, resistance to the biotrophic fungus Erysiphe orontii depends on SA, but not on JA-dependent sig- 
naling (35). Thomma et al. (39) suggested that resistance to necrotrophs depends largely on ethylene and JA signaling, whereas resistance to biotrophs is mostly dependent on SA signaling. Both necrotrophic and biotrophic classes of pathogens include bacteria, fungi, and oomycetes. Therefore, with respect to the role of ethylene, it is likely that the nature of the interaction with the host plant is more important than the relatedness of the pathogens (39).

Tobacco plants that are transformed with the mutant etrl-1 gene from Arabidopsis (Tetr) display strong insensitivity to ethylene (22). When such Tetr plants are grown in nonautoclaved soil, symptoms of wilting and stem necrosis develop spontaneously between 3 and 12 weeks after seed germination. From these diseased plants, several necrotizing oomycetes and fungi were isolated and demonstrated to be pathogenic on Tetr, but not on nontransformed tobacco plants $(13,22)$. These isolates were identified as Pythium sylvaticum, Pythium sp. group HS, Pythium sp. group G, Thielaviopsis basicola, F. oxysporum, F. solani, and Rhizopus stolonifer. These results suggest that ethylene-insensitive plants are unable to activate (a subset of) defense mechanisms that are normally active against different oomyceteous and fungal pathogens.

Recently, the oomycetes that were isolated from naturally infected Tetr plants were studied in detail on tobacco and Arabidop-

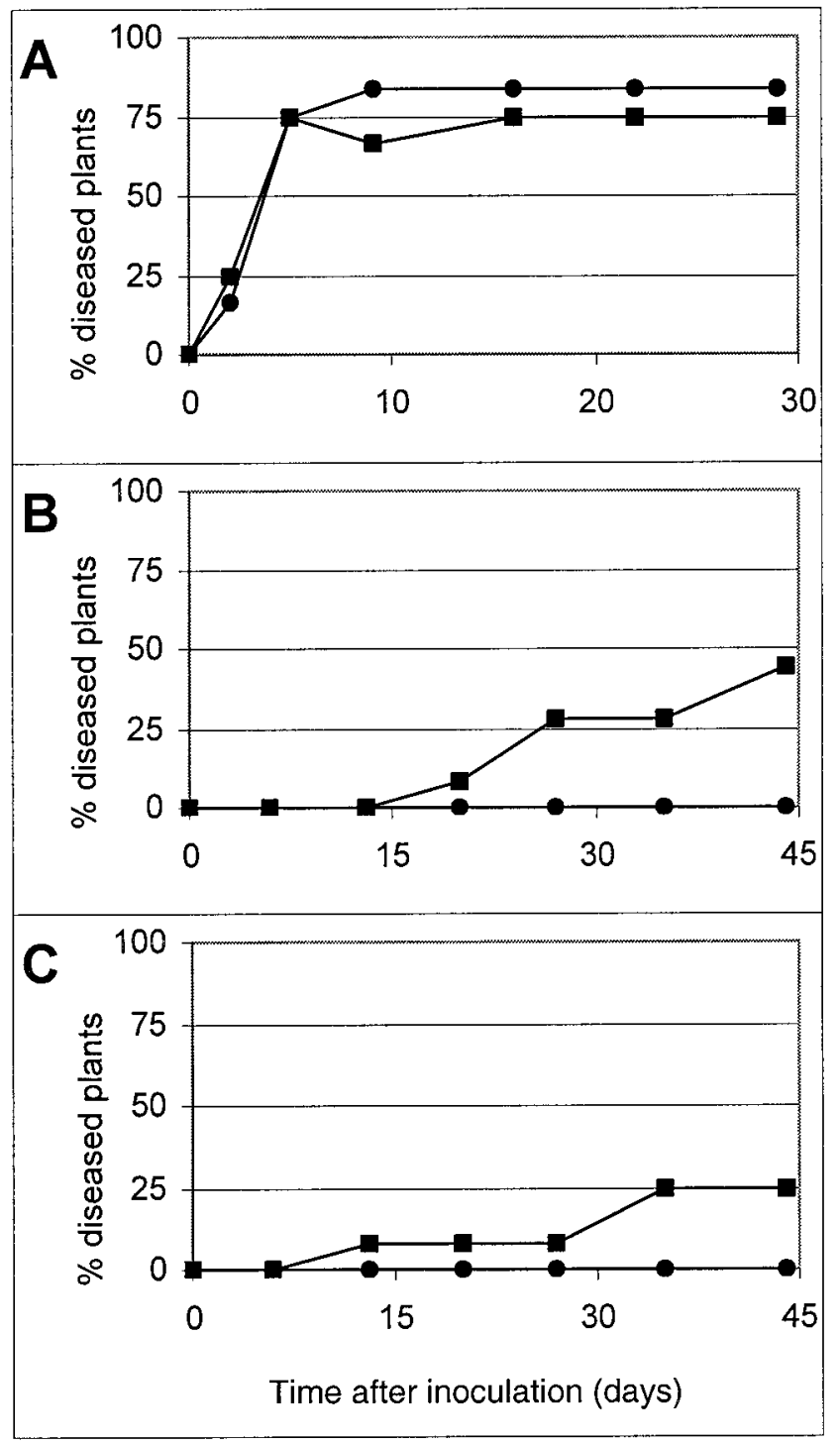

Fig. 1. Symptom development of control $(\bullet)$ and Tetr $(\bullet)$ tobacco plants after inoculation of 2-week-old seedlings with A, Thielaviopsis basicola isolate Nt29, B, Fusarium oxysporum isolate Nt32d, or $\mathbf{C}, F$. solani isolate Nt34b. sis plants (13). In this paper, the analysis was extended to the fungi that were isolated from these plants. In addition, several other pathogens were tested for pathogenicity on nontransformed and ethylene-insensitive tobacco. To determine the generality of the results obtained, the same or comparable pathogens were examined on Arabidopsis and its ethylene-insensitive mutants etrl-1 and ein2-1.

\section{MATERIALS AND METHODS}

Plant material. Seeds of transgenic ethylene-insensitive Tetr18-5 (22) and its corresponding control (Nicotiana tabacum cv. Samsun $\mathrm{NN}$ ) plants were sown in autoclaved potting soil mixed with halfstrength Hoagland nutrient solution $(70 \mathrm{ml} / \mathrm{kg}$ of soil). Plants were grown in a temperature-regulated greenhouse maintained at $24^{\circ} \mathrm{C}$ during the day and $21^{\circ} \mathrm{C}$ at night. If necessary, the photoperiod was extended to $16 \mathrm{~h}$ by additional illumination. Generally, in assays with root pathogens, 2-week-old seedlings were uprooted, inoculated as described below, and transplanted individually into 0.6-liter pots containing autoclaved soil. In assays with leaf pathogens, 2-week-old seedlings were planted out with a density of approximately 380 plants per $\mathrm{m}^{2}$. After an additional 2 weeks, the plants were transplanted into 0.6-liter pots containing autoclaved soil.

For bioassays with Peronospora tabacina, tobacco seeds were surface-sterilized by immersion in $4 \% \mathrm{NaClO}$ for $20 \mathrm{~min}$, rinsed with sterile water, and sown on Murashige and Skoog (MS) agar medium (30). After 3 weeks, the seedlings were transplanted into microtiter plate wells containing MS agar medium and inoculated.

Bioassays with Ralstonia solanacearum were performed in a growth chamber with an 8 -h light $/ 23^{\circ} \mathrm{C}$ and 16 -h dark $/ 20^{\circ} \mathrm{C}$ cycle. Two-week-old tobacco seedlings were inoculated and transplanted into 0.1-liter pots.

Seeds of wild-type Arabidopsis thaliana, ecotype Col-0, and its ethylene-insensitive mutants etrl-1 and ein2-1 were sown in autoclaved sand mixed with half-strength Hoagland nutrient solution $(300 \mathrm{ml} / \mathrm{kg})$. Plants were grown in a growth chamber with an 8-h light $/ 24^{\circ} \mathrm{C}$ and $16-\mathrm{h}$ dark $/ 21^{\circ} \mathrm{C}$ cycle. Two-week-old seedlings were inoculated and transplanted into 0.1-liter pots containing an autoclaved mixture of potting soil and river sand (12:5, vol/vol).

Pathogen cultures and inoculum preparation. $T$. basicola isolate Nt29 (13) was grown on potato dextrose agar (PDA, Difco Laboratories, Detroit) medium at $23^{\circ} \mathrm{C}$ for 2 weeks. Conidia were washed off the agar plates with $10 \mathrm{mM} \mathrm{MgSO}_{4}$ and the suspension was adjusted to a concentration of $10^{6}$ conidia per ml. Inoculation was performed by dipping seedling roots for approximately $1 \mathrm{~s}$ in the conidial suspension.

F. solani isolate $\mathrm{Nt34b}, F$. oxysporum isolate $\mathrm{Nt32d}(13), F$. oxysporum f. sp. nicotianae (CBS 179.32), F. oxysporum f. sp. lycopersici (28), F. oxysporum f. sp. matthiolae (CBS 247.61), F. oxysporum f. sp. dianthi WCS816 (41), F. oxysporum f. sp. lini Foln3 (25), and F. oxysporum f. sp. raphani strain WCS600 (24) were grown in liquid Czapek Dox medium on an orbital shaker at 100 to $150 \mathrm{rpm}$ and $24^{\circ} \mathrm{C}$ for 1 week. Mycelium was removed by filtering through glass wool. The conidia-containing filtrates were centrifuged at $8,000 \times g$ for $20 \mathrm{~min}$. The pellets were washed by resuspension in $10 \mathrm{mM} \mathrm{MgSO}_{4}$ and centrifuged at $8,000 \times g$ for $20 \mathrm{~min}$. The pellets were then suspended in $10 \mathrm{mM} \mathrm{MgSO}_{4}$ and adjusted to a concentration of $10^{6}$ conidia per ml. Root inoculation was performed by dipping seedling roots for approximately $1 \mathrm{~s}$ in the conidial suspension.

B. cinerea isolate R16 (12) was grown on PDA at $23^{\circ} \mathrm{C}$ for 2 weeks. Conidia were washed off the agar plates with half-strength potato dextrose broth medium. The suspension was filtered through one layer of Miracloth (Calbiochem, La Jolla, CA) to remove mycelium and adjusted to a concentration of $10^{6}$ conidia per ml. Four-week-old plants were inoculated by pipetting a $20-\mu \mathrm{l}$ 
droplet of the suspension on each of four leaves per plant and placed at $100 \%$ relative humidity $(\mathrm{RH})$ for 2 to 4 days.

Cercospora nicotianae (ATCC 18366) was plated onto clarified V8-juice (20\% [vol/vol] V8 juice plus $0.05 \mathrm{M} \mathrm{CaCO}_{3}, \mathrm{pH} 7.3$ ) agar medium and grown at $18^{\circ} \mathrm{C}$ for 6 days. Spores were harvested by flooding the agar plates with sterile water and brushing gently with an artist's brush. The suspension was filtered through a layer of cheesecloth to remove mycelium and adjusted to a concentration of 2 to $3 \times 10^{4}$ spores per ml. Seven-week-old plants were inoculated by spraying three leaves per plant with approximately $0.8 \mathrm{ml}$ of spore suspension per leaf and placed at $100 \%$ RH for 4 days.

Spores of Peronospora tabacina isolate Ky79 (26) were obtained by rinsing infected tobacco leaves carrying sporangiophores of the pathogen with sterile water. Inoculation was performed by spraying sterile-grown 3 -week-old plants with a suspension of $5 \times 10^{4}$ spores per $\mathrm{ml}$ of water.

Ralstonia solanacearum isolate Rrp (34) was grown on modified Kelman (20) agar medium (1\% [wt/vol] proteose peptone (Oxoid), $0.5 \%$ [wt/vol] casamino acids [Oxoid], 1\% [wt/vol] glucose, and $1.2 \%$ [wt/vol] agar) at $28^{\circ} \mathrm{C}$ for $48 \mathrm{~h}$. Agar plates were rinsed with sterile $10 \mathrm{mM} \mathrm{MgSO}$, the bacterial density was determined spectrophotometrically at $660 \mathrm{~nm}$ (34), and the suspension was adjusted to $10^{8} \mathrm{CFU} / \mathrm{ml}$. Inoculation was performed by dipping seedling roots for about $1 \mathrm{~s}$ in the bacterial suspension. Because Ralstonia solanacearum prefers relatively high temperatures, after inoculation the day and night temperatures for plant growth were shifted to 28 and $25^{\circ} \mathrm{C}$, respectively.

Erwinia carotovora pv. carotovora strain SSC3193 (33) inoculum was prepared as described by Norman-Setterblad et al. (31). Plants of 4 to 5 weeks old were inoculated by pipetting a $20-\mu \mathrm{l}$ droplet containing $8 \times 10^{6} \mathrm{CFU}$ at the center of each of four leaves per plant and placed at $100 \%$ RH for 3 days.

Oidium neolycopersici (17) inoculation was performed by transferring 9-week-old plants to a heavily infested greenhouse compartment (Ghent University, Belgium) where the pathogen was maintained on tomato cv. Moneymaker.

TMV inoculation was performed by rubbing Carborundumdusted leaves of 8 -week-old plants with purified virus solution $(2 \mu \mathrm{g} / \mathrm{ml})$ and rinsing with water (22).

Assessment of disease symptoms and statistical analysis. After inoculation of seedling roots with T. basicola, Fusarium spp., or Ralstonia solanacearum, percentages of plants showing symptoms of wilting and necrosis were determined at different time intervals. At the last time point, fresh weights of the shoots were determined. Twelve tobacco and between 15 and $20 \mathrm{Arabi}$ dopsis plants were used for each treatment. Percentages of diseased plants were statistically analyzed using the repeated measures option of SPSS for Windows, release 8.0. Fresh weights were statistically analyzed by independent samples $t$ tests with Bonferroni correction.

In the bioassays with leaf pathogens, symptoms were scored and analyzed depending on the nature of the pathogen. Eight days after inoculation of 12 nontransformed and 12 Tetr plants with $B$. cinerea, the percentage of lesions per plant that had spread from the point of inoculation was determined and statistically analyzed by independent samples $t$ test. Disease severity after infection with $C$. nicotianae or TMV was quantified by measuring lesion diameters at 3 weeks or 6 days after inoculation, respectively. For each treatment, three leaves on four (C. nicotianae) or three (TMV) plants per treatment were used. Data from over 50 lesions per treatment were statistically analyzed using the general factorial analysis of variance option to take into account possible effects of leaf age. Three days after inoculation with Erwinia carotovora, the percentage of inoculated leaves that had completely rotten was determined for 20 plants per treatment, and data were statistically analyzed by independent samples $t$ test. A leaf was considered entirely rotten when decay had progressed up to the stem. Disease development on infection with $O$. neolycopersici was quantified after 15 days using disease classes (14) that reflect the percentage of leaf area covered by the fungus: 0 , no symptoms; 1 , less than $5 \%$ of the leaf surface covered with fungal mycelium; 2,6 to $25 \%$ covered; 3,26 to $50 \%$ covered; and 4, more than $50 \%$ covered. Disease indexes were calculated as described by Hennin et al. (14) and statistically analyzed using the Mann-Whitney U-test. Disease severity on infection with Peronospora tabacina was determined by counting the numbers of sporangia that were rinsed from six individual plants per treatment at 7 days after inoculation. Data were analyzed by independent samples $t$ test.

All bioassays were repeated at least once with similar results. All statistics were performed using the software of SPSS for Windows, release 10.0.

Peroxidase activity. From eight plants, six leaf disks $(0.5-\mathrm{cm}$ diameter) per plant were sampled and frozen in liquid nitrogen. In case of infection with $B$. cinerea, the leaf disks were cut at a distance of 2 to $4 \mathrm{~mm}$ from the edge of the (spreading) lesion. Leaf disks were homogenized in $1 \mathrm{ml}$ of ice-cold $10 \mathrm{mM}$ sodium phosphate buffer, $\mathrm{pH} 6.0$, and centrifuged at $9,000 \times g$ for $10 \mathrm{~min}$. Fifty microliters of the supernatant was added as crude enzyme extract to a mixture of $1.35 \mathrm{ml}$ of $10 \mathrm{mM}$ sodium phosphate buffer, $\mathrm{pH} 6.0,50 \mu \mathrm{l}$ of a saturated solution of guaiacol in water, and $50 \mu \mathrm{l}$ of $0.5 \% \mathrm{H}_{2} \mathrm{O}_{2}$. The formation of tetraguaiacol was followed spectrophotometrically and peroxidase activity was expressed as the change in absorbance at $470 \mathrm{~nm}$ per $\mathrm{mg}$ fresh weight per minute.

\section{RESULTS}

Fungi isolated from naturally infected Tetr tobacco. When oomycetes and fungi previously isolated from spontaneously diseased Tetr plants were used to inoculate nontransformed and Tetr tobacco plants of 6 weeks old, only the latter developed symptoms of disease (13). However, when 2-week-old seedlings were inoculated with two of these isolates (both Pythium spp.), a small percentage of the nontransformed control plants also developed symptoms of disease, indicating that the Pythium spp. are weak opportunistic pathogens for nontransformed tobacco under seedling conditions. Therefore, T. basicola, F. oxysporum, and $F$. solani were tested to determine to what extent they can cause disease not only in Tetr but also in nontransformed seedlings.

When 2-week-old tobacco seedlings were inoculated by dipping the roots in a spore suspension of T. basicola isolate $\mathrm{Nt29}$, both control and Tetr plants developed severe symptoms of wilting and necrosis within 2 days. The percentages of diseased control and Tetr plants stabilized by 5 days after inoculation at about $80 \%$ and eventually most plants died. The disease progress curves of control and Tetr plants in Figure 1A reflect the percentages of plants with disease symptoms, varying from wilting to dead. Although tested with repeated time measures, there was no significant difference in symptom development between the control and Tetr plants. Almost all Thielaviopsis-inoculated plants remained minute or died at the seedling stage, resulting in final shoot fresh weights below $0.5 \mathrm{~g}$ per plant (Table 1 ).

TABLE 1. Average shoot fresh weights (grams) of nontransformed (control) and Tetr tobacco plants infected with Thielaviopsis sp. at 29 days after inoculation or with Fusarium spp. at 44 days after inoculation ${ }^{\mathrm{a}}$

\begin{tabular}{llll}
\hline & \multicolumn{1}{c}{ Control } & Tetr18 \\
\hline Mock & 27.0 & 22.0 \\
T. basicola isolate Nt29d & $<0.5 \quad(P<0.01)$ & $<0.5 \quad(P<0.01)$ \\
Mock & 84.0 & 87.0 \\
F. oxysporum isolate Nt32d & $86.0 \quad(P=0.38)$ & $67.0 \quad(P=0.06)$ \\
F. solani isolate Nt34b & $86.0 \quad(P=0.34)$ & $68.0 \quad(P=0.05)$ \\
\hline
\end{tabular}

${ }^{a} P$ indicates the level of difference from the noninfected (mock) plants. 
In contrast to the rapid symptom development in both control and Tetr plants infected with T. basicola, inoculation of tobacco seedlings with $F$. oxysporum isolate Nt32d (Fig. 1B) or F. solani isolate $\mathrm{Nt34b}$ (Fig. 1C) resulted in a slow development of wilting symptoms in a relatively small percentage of the Tetr plants only. Nontransformed control plants did not develop any symptoms. Therefore, there was too little homogeneity of variances to perform statistics using repeated time measures. However, $t$ tests revealed that the percentage of diseased Tetr plants was significantly increased by 44 days after infection with $F$. oxysporum isolate Nt32d $(P<0.01)$ or $F$. solani isolate Nt34b $(P=0.06)$. Both isolates reduced shoot fresh weights of Tetr plants but not of nontransformed plants (Table 1). These results agree with the enhanced susceptibility of Tetr plants to these isolates as observed previously (13).

To elucidate if ethylene insensitivity results in enhanced susceptibility to these fungi in other plant species as well, the isolates were inoculated on 2-week-old seedlings of Arabidopsis and its ethylene-insensitive mutants etrl-1 and ein2-1. The isolate of $T$. basicola was less pathogenic on Arabidopsis than on tobacco and no more than half of the plants developed symptoms of disease (Fig. 2). Wild-type plants started to wilt earlier than the etr $1-1$ and ein2-1 mutants (Fig. 2), and by 5 days after inoculation, the percentage of wilted wild-type plants was higher than that of the mutants. However, all wild-type plants recovered within the subsequent 3 weeks, whereas about $50 \%$ of both mutants eventually developed symptoms and did not recover. In accordance, $10 \%$ of the etrl-1 and $30 \%$ of the ein2-1 mutants died. The transient wilting of the wild-type plants was associated with a reduction in final shoot fresh weight similar to the reduction in shoot fresh weights of the ethylene-insensitive mutants (data not shown). Apparently $T$. basicola acts as a weak opportunistic pathogen on wild-type Arabidopsis seedlings but is more virulent on the ethylene-insensitive mutants.

Inoculation of Arabidopsis seedlings with F. oxysporum isolate $\mathrm{Nt32d}$ or $F$. solani isolate $\mathrm{Nt34b}$ did not cause any symptoms of

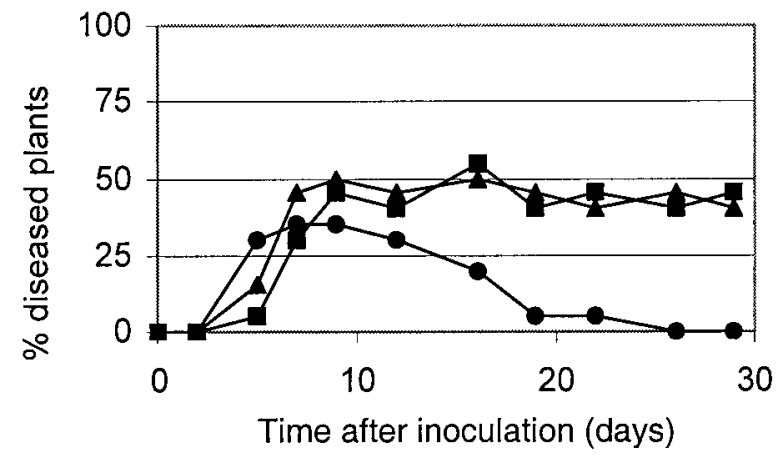

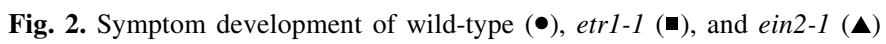
Arabidopsis plants after inoculation of 2-week-old seedlings with Thielaviopsis basicola isolate $\mathrm{Nt} 29$. disease in either wild-type plants or the ethylene-insensitive mutants (Table 2).

Formae speciales of $\boldsymbol{F}$. oxysporum. Many soilborne pathogens are able to infect and cause disease in a broad range of host plants. In contrast, specific formae speciales of $F$. oxysporum are adapted to infect one or a few plant species only. To investigate whether ethylene insensitivity results in susceptibility to formae speciales that are specific to other host plants, pathogenicity of five formae speciales of $F$. oxysporum was tested in control and ethyleneinsensitive seedlings of tobacco and Arabidopsis. In tobacco, none of the selected non-host pathogens caused symptoms of disease in either control or Tetr plants (Table 2). Similarly, the non-host pathogens of Arabidopsis were virulent neither on wild-type Arabidopsis nor on its ethylene-insensitive mutants.

The Fusarium isolates from naturally infected Tetr tobacco did not cause disease in Arabidopsis spp. Therefore, Fusarium isolates that are pathogenic on Arabidopsis were selected in addition to the non-host pathogens (Table 2). F. oxysporum f. sp. raphani has been demonstrated to cause vascular wilt in Arabidopsis (32) and appeared to be significantly more virulent on wild-type plants than on its ethylene-insensitive mutants etr $1-1$ and ein2-1 (Table 2; Fig. 3A). Initially, wild-type plants and the mutants developed symptoms of wilting and necrosis to similar extents. In addition, strong leaf chlorosis around the veins was noticed in infected wild-type plants. In the ethylene-insensitive mutants, chlorosis was less obvious or absent. By 5 weeks after inoculation, symptom development in the etr $1-1$ and ein2-1 mutants stabilized at approximately $40 \%$ diseased plants. Within another 2 weeks, all wild-type plants died, as clearly reflected by the final average fresh weight of less than $0.1 \mathrm{~g}$ per plant (Table 3 ).

Because $F$. oxysporum f. sp. matthiolae has been described as a necrotrophic pathogen on Arabidopsis (11), it was tested as well. The isolate did not cause disease symptoms in wild-type plants or in the etr1-1 mutants, but a few ein2-1 plants showed clear symptoms of necrosis (Table 2; Fig. 3B). In the etr 1-1 mutants, a slight reduction in fresh weight was observed (Table 3), even though symptoms of disease were not apparent. These data suggest that $F$. oxysporum f. sp. matthiolae interacts differently with Arabidopsis than F. oxysporum f. sp. raphani. Apparently, ethylene signaling in Arabidopsis can increase or reduce susceptibility to $F$. oxysporum, depending on the kind of interaction between the fungus and its host. Ethylene signaling does not seem to impair resistance to nonhost Fusarium spp.

Necrotrophic pathogens. To investigate whether the differences in disease susceptibility between nontransformed and Tetr tobacco also occur after infection with other necrotrophic pathogens, two fungal and two bacterial pathogens of tobacco were tested. As fungal leaf pathogens, the gray mold fungus, $B$. cinerea, and the leaf spot fungus, $C$. nicotianae, were used. Upon inoculation with $B$. cinerea, a necrotic lesion developed under the inoculation droplet in both control and Tetr plants within 2 days. In control plants, these lesions almost always remained limited. In contrast, on Tetr plants the majority of the lesions quickly spread (Fig. 4A). Frequently, the fungus fully colonized the Tetr leaves and grew further into the stem. If the pathogen colonized the stem

TABLE 2. Fusarium isolates tested for pathogenicity on control and ethylene-insensitive tobacco and Arabidopsis plants ${ }^{\mathrm{a}}$

\begin{tabular}{|c|c|c|c|c|c|c|c|}
\hline & \multirow[b]{2}{*}{ Host } & \multicolumn{2}{|c|}{ Tobacco } & \multirow[b]{2}{*}{ Host } & \multicolumn{3}{|c|}{ Arabidopsis } \\
\hline & & Control & Tetr18 & & Col-0 & etr $1-1$ & ein2-1 \\
\hline F. oxysporum isolate $\mathrm{Nt} 32 \mathrm{~d}$ & $?$ & - & + & No & - & nd & - \\
\hline F. solani isolate $\mathrm{Nt} 34 \mathrm{~b}$ & $?$ & - & + & No & - & nd & - \\
\hline F. oxysporum f. sp. dianthi & No & - & - & No & - & - & - \\
\hline F. oxysporum f. sp. lini & No & - & - & No & - & - & - \\
\hline F. oxysporum f. sp. lycopersici & No & - & - & No & - & - & - \\
\hline F. oxysporum f. sp. matthiolae & No & - & - & Yes & - & - & + \\
\hline F. oxysporum f. sp. raphani & No & - & - & Yes & ++ & + & + \\
\hline
\end{tabular}

a ?, unknown; - , no disease symptoms;,$+<50 \%$ of plants with symptoms of wilting;,$++>50 \%$ of plants with symptoms of wilting; and nd, not determined. 
tissue, Tetr plants eventually died due to progressive stem necrosis. In those rare cases where the fungus colonized a complete leaf and reached the stem of a nontransformed plant, it did not grow further and was restricted to a black lesion at the base of the petiole (Fig. 5).

After spraying leaves with a spore suspension of $C$. nicotianae, lesions developed in control and Tetr plants within 2 weeks. The lesions spread and after 3 weeks the lesions on leaves of Tetr plants were over $50 \%$ larger than those on leaves of control plants (Fig. 4B). Thus, ethylene-insensitive Tetr plants are less capable of restricting leaf colonization by $B$. cinerea and $C$. nicotianae than nontransformed control plants.

Inoculation with Erwinia carotovora, causal agent of soft rot in numerous plant species (2), was performed by applying droplets of bacterial suspension on the leaves. Patches of rotting tissue developed within $24 \mathrm{~h}$ in both control and Tetr plants but enlarged faster in leaves of Tetr plants. The percentage of decayed leaves by 3 days after inoculation was significantly higher in the ethylene-insensitive Tetr plants (Fig. 4C). Occasionally, the bacterium colonized the stem, sometimes resulting in plant death. By 8 days after inoculation, $55 \%$ of the Tetr plants had decayed completely, whereas all nontransformed plants were still alive. Thus, the reduced capability of Tetr plants to restrict colonization by necrotrophic pathogens extends to this bacterium as well.

The bacterial root pathogen Ralstonia solanacearum, causal agent of bacterial wilt, was inoculated onto 2-week-old seedlings. First symptoms of wilting were observed in both nontransformed and Tetr plants by 5 days after inoculation (data not shown). Disease symptoms developed faster on Tetr plants than on nontransformed plants. Symptom development of Tetr plants stabilized at approximately $70 \%$ of wilted plants by 10 days after inoculation. Symptom development of nontransformed plants reached a similar level after 3 weeks (data not shown). Thus, Tetr plants appeared to be more sensitive to Ralstonia solanacearum. Although this tendency was observed in all three experiments, differences were rather small and nonsignificant as tested by repeated measures.

Biotrophic pathogens. In contrast to necrotrophic pathogens that produce cell wall degrading enzymes and/or toxins to invade and destroy host cells, biotrophic pathogens essentially avoid triggering host defense responses. To investigate whether ethylene-insensitive tobacco plants are more susceptible to biotrophs as well, the powdery mildew fungus of tomato, O. neolycopersici, and the downy mildew oomycete Peronospora tabacina were tested. For comparison, TMV, which triggers a hypersensitive response (HR) in cv. Samsun NN tobacco, was tested as a representative virus.

When tobacco plants were transferred to a greenhouse with a high natural disease pressure of $O$. neolycopersici, colonies of white mycelium developed on leaves of both control and Tetr plants. Using a disease index that reflects the percentage of leaf area covered by the fungus, no significant difference in susceptibility between control and Tetr tobacco plants was evident (Fig. 4D). Colonization of the plants by Peronospora tabacina was estimated by counting the number of sporangia that were produced on the leaves. Tetr plants allowed significantly less sporulation than control plants (Fig. 4E), suggesting reduced colonization by Peronospora tabacina. Apparently, ethylene insensitivity results in increased resistance to this oomyceteous pathogen. These results indicate that loss of ethylene perception in tobacco does not enhance susceptibility to biotrophic pathogens.

Tobacco cv. Samsun NN contains the resistance gene $N$ and, consequently, displays an HR after infection with TMV. In agreement with previous findings (22), both control and Tetr leaves that were inoculated with TMV developed necrotic lesions within 2 days. By 6 days, the lesions on Tetr leaves had remained significantly smaller than those on leaves of control plants (Fig. 4F), confirming that ethylene perception does not contribute to lesion limitation during TMV infection (21).
Peroxidase activity. Total peroxidase activity can serve as a useful marker for disease resistance (36). Tobacco plants that are infected with different necrotizing pathogens show enhanced levels of peroxidase activity (29). Therefore, it was investigated whether peroxidase activity of Tetr plants differed from that of nontransformed plants. Indeed, basal peroxidase activity in leaves of Tetr plants was only about $40 \%$ of that in leaves of nontransformed control plants (Fig. 6A). After inoculation with $B$. cinerea, Tetr plants were still able to activate peroxidase activity in the leaf cells bordering the site of infection (Fig. 6B). Whereas the peroxidase activity in nontransformed plants increased 15 -fold on Botrytis infection, Tetr plants showed a 25 -fold increase in activity. However, the final enzyme activity in Tetr plants was still significantly lower (minus 27\%) than in control plants.

\section{DISCUSSION}

Ethylene-insensitive tobacco plants were demonstrated to be naturally infected by at least three unrelated genera of root pathogens present in the same batch of potting soil $(13,22)$. In this study, we investigated how wide the range of pathogens is to which ethylene-insensitive tobacco plants display enhanced disease susceptibility. Besides the Pythium isolates studied earlier (13), T. basicola, F. solani, and F. oxysporum were tested, as well as various selected, nonrelated fungal and bacterial pathogens.

The oomycetes and fungi that were isolated from diseased Tetr plants were not pathogenic on 6-week-old nontransformed tobacco plants (13). However, 2-week-old seedlings of nontransformed tobacco were also susceptible to two of the Pythium isolates. Apparently, the Pythium spp. are virulent on nontransformed tobacco seedlings but not on older plants. In contrast, ethylene-insensitive plants remain susceptible in the mature stage.

A similar difference between 6-week-old plants and 2-week-old seedlings was observed after inoculation with $T$. basicola. Although inoculation of 6-week-old plants resulted in diseased Tetr plants only (13), root inoculation of 2-week-old seedlings resulted in equally high percentages of diseased nontransformed and Tetr

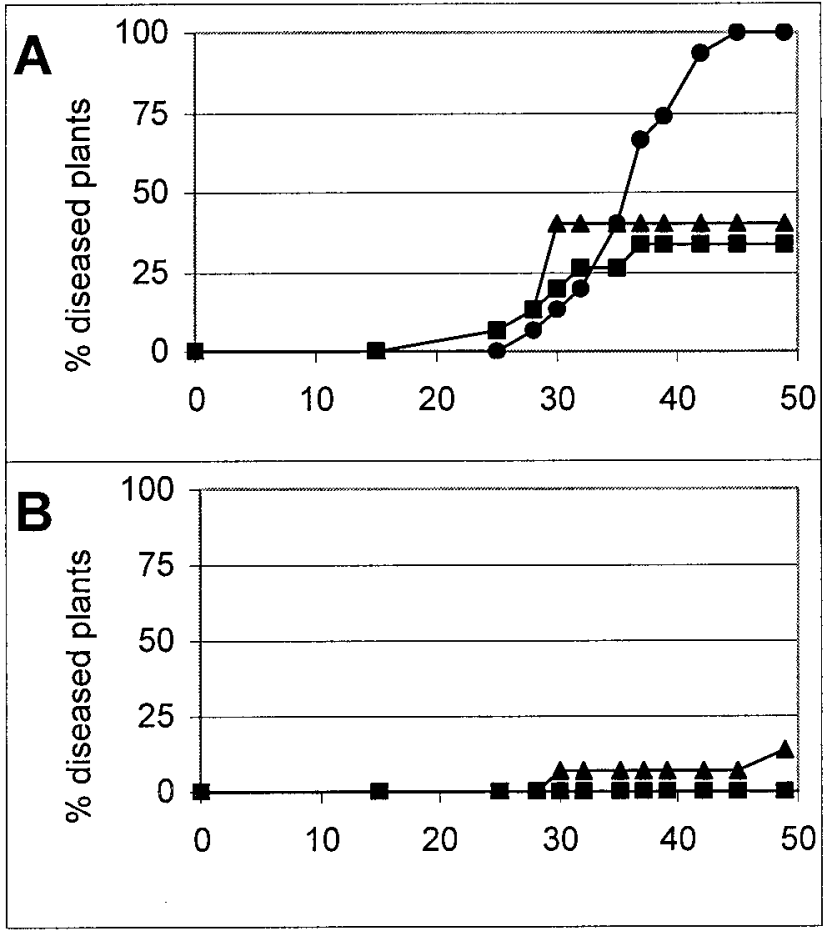

Fig. 3. Symptom development of wild-type $(\bullet)$, etr1-1 (•), and ein2-1 (ム) Arabidopsis plants after inoculation of 2-week-old seedlings with A, Fusarium oxysporum f. sp. raphani or $\mathbf{B}, F$. oxysporum f. sp. matthiolae. 
plants within a few days. Equal symptom development of control and Tetr seedlings was also observed after inoculation of 2-weekold seedlings with Pythium aphanidermatum (13). These findings may be related to the fact that both Pythium aphanidermatum and T. basicola have been described as real pathogens rather than weak opportunistic pathogens of tobacco seedlings $(2,7,8)$.

Unlike inoculation with Pythium or Thielaviopsis, inoculating 2-week-old seedlings with $F$. solani or $F$. oxysporum isolate $\mathrm{Nt} 32 \mathrm{~d}$ caused disease in Tetr plants but not in nontransformed plants. This indicates that these isolates are weak opportunistic pathogens of tobacco that display increased virulence on ethylene-insensitive Tetr plants. Five formae speciales that are pathogenic on other host plants did not cause disease symptoms in either control or Tetr tobacco. Apparently, ethylene-insensitive tobacco displays enhanced susceptibility to pathogenic and opportunistic Fusaria but is not affected by non-host pathogens.

In order to further explore the range of pathogens to which ethylene-insensitive tobacco shows altered disease resistance, several root and leaf pathogens of tobacco were selected. Infection with Ralstonia solanacearum indicated that Tetr plants are more

TABLE 3. Average shoot fresh weights (grams) of wild-type (Col-0), etrl-1, and ein2-1 Arabidopsis plants infected with pathogenic Fusarium oxysporum at 49 days after inoculation ${ }^{\mathrm{a}}$

\begin{tabular}{llll}
\hline & \multicolumn{1}{c}{ Col-0 } & etr1-1 & ein2-1 \\
\hline $\begin{array}{l}\text { Mock } \\
\text { F. oxysporum }\end{array}$ & 1.8 & 1.6 & 1.9 \\
$\quad$ f. sp. matthiolae & $1.9(P=0.23)$ & $1.2(P=0.03)$ & $1.9(P=0.65)$ \\
$\begin{array}{l}\text { F. oxysporum } \\
\quad \text { f. sp. raphani }\end{array}$ & $<0.1(P<0.01)$ & $0.5(P<0.01)$ & $0.4(P<0.01)$ \\
\hline
\end{tabular}

${ }^{a} P$ indicates the level of difference from the noninfected (mock) plants. susceptible to this bacterial root pathogen. Ethylene-insensitive tobacco plants proved more susceptible to different leaf pathogens as well. Inoculation with the fungi $B$. cinerea or $C$. nicotianae, or the bacterium Erwinia carotovora, resulted in more disease symptoms in Tetr than in control plants. Apparently, Tetr tobacco plants display enhanced susceptibility to a broad range of necrotizing pathogens. These data indicate a role for ethylene signaling in defense against necrotrophic pathogens, irrespective of the site of infection or relatedness of the pathogens.

Enhanced disease susceptibility of ethylene-insensitive tobacco plants was not observed for biotrophic pathogens. When tobacco leaves were inoculated with the biotrophic fungus $O$. neolycopersici, disease development in control and Tetr plants was similar. Inoculation with the biotrophic oomycete Peronospora tabacina resulted in even less disease development in Tetr plants. Also, the reaction to TMV infection was not impaired. These data demonstrate that ethylene-insensitive tobacco plants are not more susceptible to biotrophic pathogens, and confirm that they are still able to establish the HR. Apparently, ethylene plays a significant role in resistance to necrotrophic pathogens but not in resistance to biotrophic pathogens.

To determine whether ethylene insensitivity results in similar alterations in susceptibility to pathogens in other plant species as well, the same set of oomycetes, fungi, and bacteria was examined in Arabidopsis. Inoculation of ethylene-insensitive mutants etrl-1 and ein2-1 with $T$. basicola resulted in substantial symptom development, whereas wild-type plants developed symptoms only transiently. A similar phenomenon was observed for Pythium spp. (13). Whereas wild-type plants recovered after initial symptom development, a significant percentage of ein2-1 plants developed symptoms and did not recover after inoculation with Pythium spp. Etr1-1 mutants reacted similar as wild-type plants to Pythium
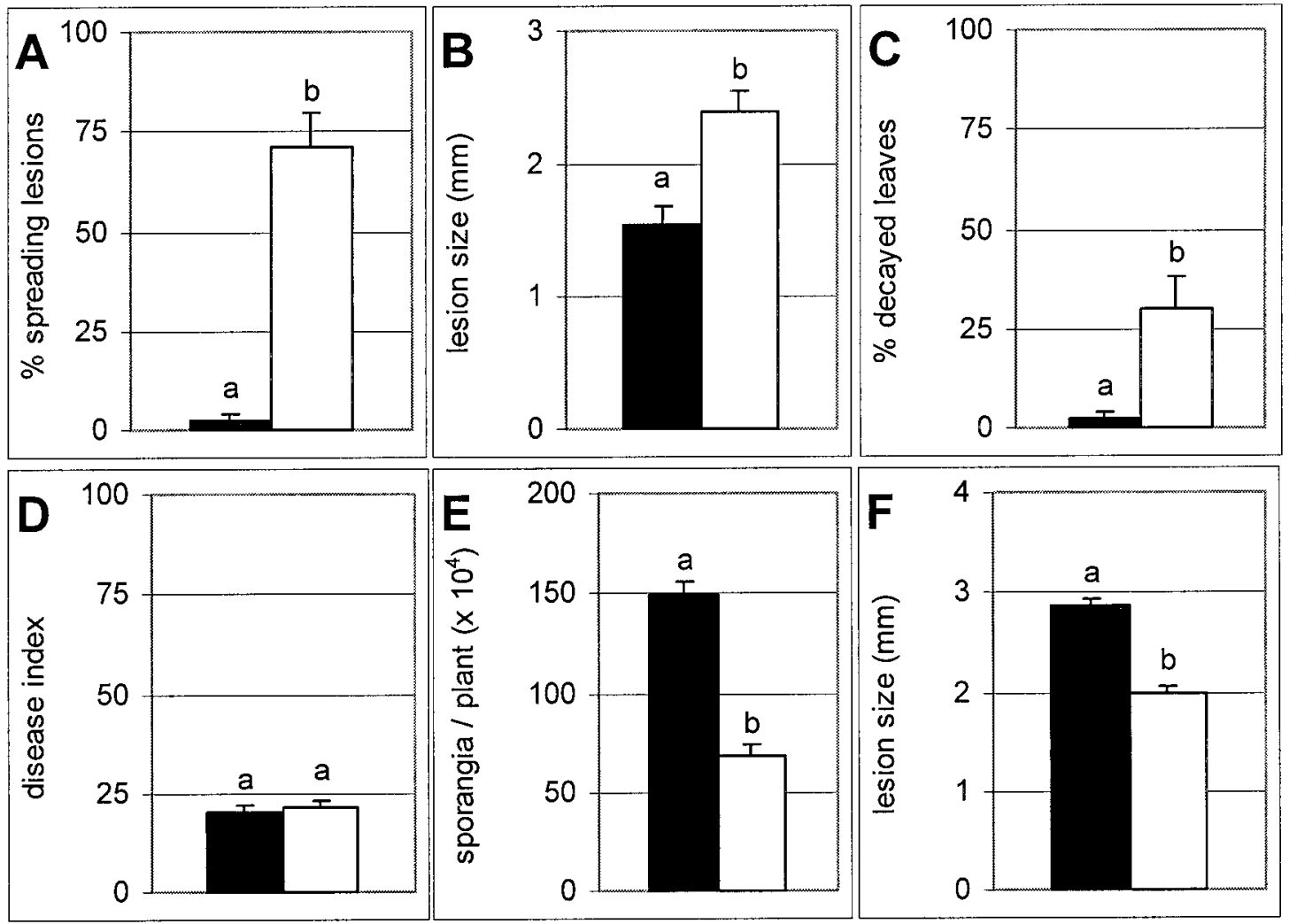

Fig. 4. Symptom development of control (black bars) and Tetr (white bars) tobacco plants after inoculation of the leaves with different pathogens. A, Percentage of spreading lesions by 8 days after droplet inoculation with Botrytis cinerea. B, Lesion diameter by 3 weeks after inoculation with Cercospora nicotianae. C, Percentage of completely rotten leaves by 3 days after inoculation with Erwinia carotovora. D, Disease index indicating the percentage of leaf area covered with Oidium lycopersici by 15 days after inoculation. E, Numbers of sporangia present on the leaves by 7 days after inoculation with Peronospora tabacina. F, Lesion diameter by 6 days after inoculation with Tobacco mosaic virus. Error bars represent standard errors and different letters indicate significant differences $(P<0.05)$ between control and Tetr plants. 
infection, presumably because etrl-1 is less insensitive to ethylene than ein2-1 (13). Inoculation with $T$. basicola revealed no difference in symptom development between etrl-1 and ein2-1 (Fig. 2). Apparently, in Arabidopsis the difference in ethylene insensitivity results in differential susceptibility to Pythium spp. but not to T. basicola. These data demonstrate that Pythium spp. and $T$. basicola, previously isolated from naturally infected Tetr tobacco, act as opportunistic pathogens on Arabidopsis under seedling conditions. Similar to Tetr tobacco, ethylene-insensitive Arabidopsis mutants display enhanced susceptibility to these isolates.

The Fusaria that were isolated from naturally infected Tetr tobacco plants were pathogenic neither on wild-type Arabidopsis nor on its ethylene-insensitive mutants. However, an isolate of $F$. oxysporum f. sp. matthiolae, described as a necrotrophic pathogen of Arabidopsis (11), caused symptoms in a few ein2-1 mutant plants. Although there was some growth reduction in mutant etrl1 , wild-type and etrl-1 plants were not diseased. This indicates that, similar to Tetr tobacco, ethylene-insensitive Arabidopsis shows enhanced susceptibility to a necrotrophic Fusarium that causes root rot. In seeming contrast, inoculation with $F$. oxysporum $\mathrm{f}$. sp. raphani resulted in a smaller percentage of diseased ethylene-insensitive mutants than wild-type plants. The chlorosis observed in the leaves of symptomatic wild-type Arabidopsis plants indicated that this isolate causes vascular wilt, typical of $F$. oxysporum, rather than root rot. Likewise, the ethylene-insensitive never-ripe mutant of tomato displays increased tolerance to the vascular wilt pathogen $F$. oxysporum f. sp. lycopersici (27). Possibly, ethylene insensitivity reduces symptom development of Fusarium wilt but increases symptom development of Fusarium root rot. This discrepancy may be explained by a difference in the localization of the Fusarium pathogens. Whereas root rot pathogens generally invade and kill cells of the epidermis and cortex, vascular wilt pathogens are present in the xylem vessels, where they interfere with the host's translocation of water and nutrients. Only at later stages do they invade and destroy surrounding parenchyma cells (2). Also, the vascular wilt bacterium Ralstonia solanacearum caused less symptoms in the ethylene-insensitive Arabidopsis mutant ein2-1 (15). The vascular localization of this bacterium may also explain the small, nonsignificant differences in symptom development between nontransformed and Tetr tobacco. These data indicate that the effect of ethylene signaling on disease development depends on the kind of interaction rather than the pathogen species involved.

Our results with ethylene-insensitive tobacco are in line with the earlier reported enhanced susceptibility of ethylene-insensitive Arabidopsis mutants to specific pathogens. Ethylene-insensitive ein2-1 mutants of Arabidopsis are, like Tetr tobacco, more susceptible to B. cinerea (38) and Erwinia carotovora (31). Tetr tobacco plants showed similar and less symptoms after infection with the biotrophic pathogens $O$. neolycopersici and Peronospora tabacina, respectively. The ethylene-insensitive Arabidopsis mutants etrl-1 and $e i n 2-1$ are as susceptible as wild-type plants to the biotrophic oomycete Peronospora parasitica (23). The HR upon inoculation with TMV was unaltered in ethylene-insensitive Tetr tobacco, as was the HR after inoculation with Turnip crinkle virus in ethylene-insensitive Arabidopsis (etrl-1 [Col-0] $\times$ Di-17) (18). Our results support the idea that ethylene signaling in tobacco and Arabidopsis broadly functions in a similar fashion in defense against a broad spectrum of necrotrophic pathogens (13). However, care should be taken not to generalize too much, as exemplified by the apparent exception for necrotrophic vascular pathogens. Thomma et al. (39) also recognized that ethylene signaling is involved in defense against necrotrophic, but not biotrophic pathogens, although they stress that different signal-transduction

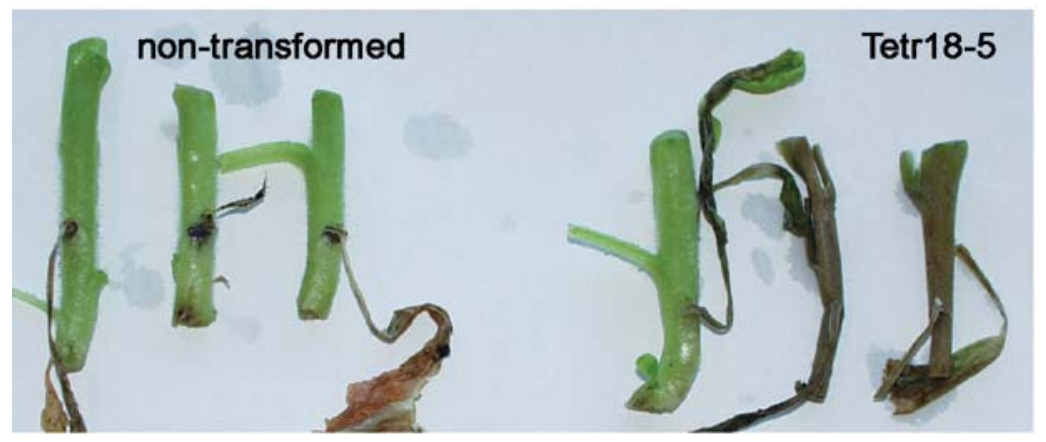

Fig. 5. Control and Tetr tobacco stem pieces bearing a leaf that has completely decayed as a result of infection by Botrytis cinerea. In control plants fungal invasion was stopped when it reached the stem, whereas Tetr plants were colonized completely and developed severe stem rot.
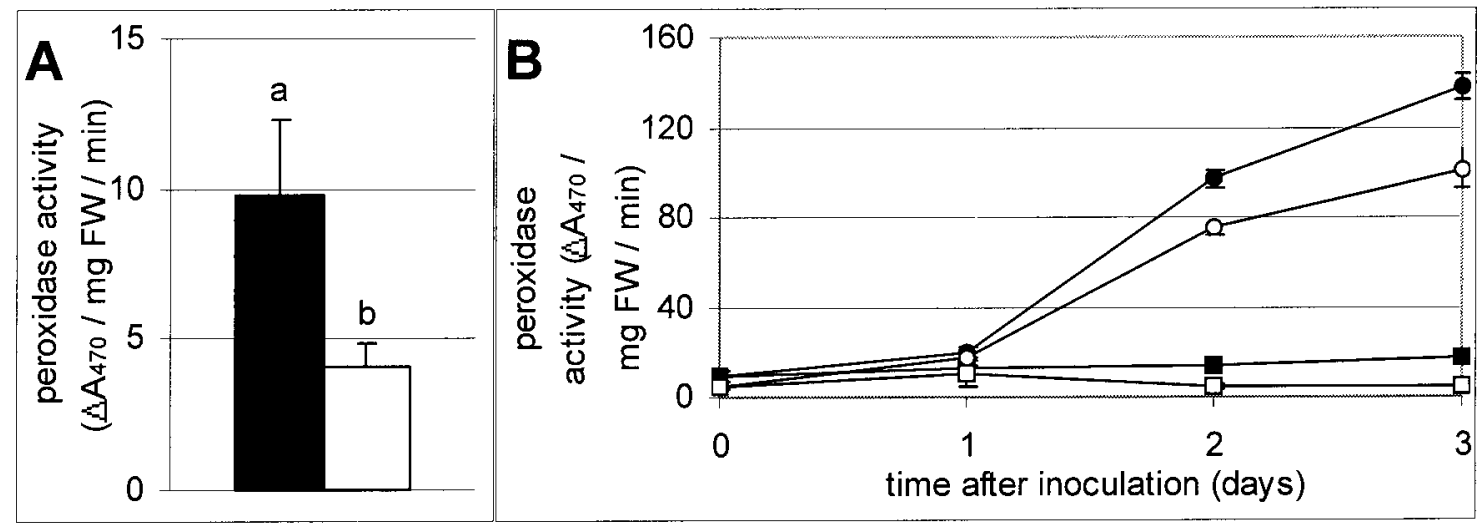

Fig. 6. A, Basal peroxidase activity in leaves of control (black bar) and Tetr (white bar) tobacco plants. B, Peroxidase activity in mock-inoculated leaf tissue $(\square, \bullet)$ and leaf tissue surrounding lesions caused by Botrytis cinerea $(\circ, \bullet)$ on nontransformed $(\bullet, \bullet)$ and Tetr $(\square, \bigcirc)$ tobacco plants. Error bars represent standard errors and different letters indicate significant differences $(P<0.05)$ between control and Tetr plants. 
routes might interfere with each other. In addition, ethylene can modulate the expression of disease symptoms $(6,21,27)$.

Peroxidase activity is often used as a marker for disease resistance (36). Tetr tobacco plants possess reduced peroxidase activity, which has also been demonstrated for ethylene-insensitive Arabidopsis mutant etrl-1 (4). Transgenic tobacco plants with enhanced levels of peroxidase activity have been shown to be more resistant to $C$. nicotianae (42), Erwinia carotovora (10), and Phytophthora parasitica $(19,42)$. As demonstrated in tobacco with different necrotizing pathogens (29), infection with $B$. cinerea resulted in increased peroxidase activity. However, the increase in Tetr plants did not reach the level observed in nontransformed control plants. These results suggest that Tetr plants may be impaired in defense reactions involving peroxidase activity. Clarifying the mechanisms of resistance that are impaired in these plants may contribute to the development of strategies to increase resistance against necrotrophic pathogens.

\section{ACKNOWLEDGMENTS}

This research was financially supported by the Earth and Life Sciences Foundation (ALW), which is subsidized by the Netherlands Organization for Scientific Research (NWO). We thank M. Daub (North Carolina State University, U.S.A.), T. Palva (University of Helsinki, Finland), and L. Ran (Central South Forestry College, P.R. China) for providing the isolates of C. nicotianae, Erwinia carotovora, and Ralstonia solanacearum, respectively; and M. Knippenberg (University of Kaiserslautern) for technical assistance.

\section{LITERATURE CITED}

1. Abeles, F. B., Morgan, P. W., and Saltveit, M. E., Jr. 1992. Ethylene in Plant Biology. Academic Press, San Diego.

2. Agrios, G. N. 1997. Plant Pathology. 4th ed. Academic Press, San Diego.

3. Bent, A. F., Innes, R. W., Ecker, J. R., and Staskawicz, B. J. 1992. Disease development in ethylene-insensitive Arabidopsis thaliana infected with virulent and avirulent Pseudomonas and Xanthomonas pathogens. Mol. Plant-Microbe Interact. 5:372-378.

4. Bleecker, A. B., Estelle, M. A., Somerville, C., and Kende, H. 1988. Insensitivity to ethylene conferred by a dominant mutation in Arabidopsis thaliana. Science 241:1086-1089.

5. Bleecker, A. B., and Kende, H. 2000. Ethylene: A gaseous signal molecule in plants. Annu. Rev. Cell Dev. Biol. 16:1-18.

6. Boller, T. 1991. Ethylene in pathogenesis and disease resistance. Pages 293-314 in: The Plant Hormone Ethylene. K. Mattoo and J. C. Suttle, eds. CRC Press, Boca Raton, FL.

7. Cartwright, D. K., Spurr, H. W., Jr., and Shew, H. D. 1995. Commercial potting medium as the source of Pythium causing a disease on tobacco transplants. Plant Dis. 79:538.

8. Chen, J., Jacobson, L. M., Handelsman, J., and Goodman, R. M. 1996. Compatibility of systemic acquired resistance and microbial biocontrol for suppression of plant disease in a laboratory assay. Mol. Ecol. 5:73-80.

9. Díaz, J., Ten Have, A., and Van Kan, J. A. L. 2002. The role of ethylene and wound signaling in resistance of tomato to Botrytis cinerea. Plant Physiol. 129:1341-1351.

10. Elfstrand, M., Sitbon, F., Lapierre, C., Bottin, A., and Von Arnold, S. 2002. Altered lignin structure and resistance to pathogens in spi2-expressing tobacco plants. Planta 214:708-716.

11. Epple, P., Apel, K., and Bohlmann, H. 1997. Overexpression of an endogenous thionin enhances resistance of Arabidopsis against Fusarium oxysporum. Plant Cell 9:509-520.

12. Faretra, F., and Pollastro, S. 1991. Genetic bases of resistance to benzimidazole and dicarboximide fungicides in Botryotinia fuckeliana (Botrytis cinerea). Mycol. Res. 8:943-951.

13. Geraats, B. P. J., Bakker, P. A. H. M., and van Loon, L. C. 2002. Ethylene insensitivity impairs resistance to soilborne pathogens in tobacco and Arabidopsis thaliana. Mol. Plant-Microbe Interact. 15: 1078-1085.

14. Hennin, C., Diederichsen, E., and Höfte, M. 2001. Local and systemic resistance to fungal pathogens triggered by an AVR9-mediated hypersensitive response in tomato and oilseed rape carrying the $C f-9$ resistance gene. Physiol. Mol. Plant Pathol. 59:287-295.

15. Hirsch, J., Deslandes, L., Feng, D. X., Balagué, C., and Marco, Y. 2002. Delayed symptom development in ein2-1, an Arabidopsis ethylene- insensitive mutant, in response to bacterial wilt caused by Ralstonia solanacearum. Phytopathology 92:1142-1148.

16. Hoffman, T., Schmidt, J. S., Zheng, X., and Bent, A. F. 1999. Isolation of ethylene-insensitive soybean mutants that are altered in pathogen susceptibility and gene-for-gene disease resistance. Plant Physiol. 119:935-949.

17. Jones, H., Whipps, J. M., and Gurr, S. J. 2001. The tomato powdery mildew fungus Oidium neolycopersici. Mol. Plant Pathol. 2:303-309.

18. Kachroo, P., Yoshioka, K., Shah, J., Dooner, H. K., and Klessig, D. F. 2000. Resistance to turnip crinkle virus in Arabidopsis is regulated by two host genes and is salicylic dependent but NPR1, ethylene, and jasmonate independent. Plant Cell 12:677-690.

19. Kazan, K., Goulter, K. C., Way, H. M., and Manners, J. M. 1998. Expression of a pathogenesis-related peroxidase of Stylosanthes humilis in transgenic tobacco and canola and its effect on disease development. Plant Sci. 136:207-217.

20. Kelman, A. 1954. The relationship of pathogenicity in Pseudomonas solanacearum to colony appearance on a tetrazolium medium. Phytopathology 44:693-695.

21. Knoester, M., Linthorst, H. J. M., Bol, J. F., and Van Loon, L. C. 2001. Involvement of ethylene in lesion development and systemic acquired resistance in tobacco during hypersensitive reaction to tobacco mosaic virus. Physiol. Mol. Plant Pathol. 59:45-57.

22. Knoester, M., Van Loon, L. C., Van den Heuvel, J., Hennig, J., Bol, J. F., and Linthorst, H. J. M. 1998. Ethylene-insensitive tobacco lacks nonhost resistance against soil-borne fungi. Proc. Natl. Acad. Sci. USA 95:19331937.

23. Lawton, K. A., Potter, S. L., Ukness, S., and Ryals, J. 1994. Acquired resistance signal transduction in Arabidopsis is ethylene independent. Plant Cell 6:581-588.

24. Leeman, M., van Pelt, J. A., Hendrickx, M. J., Scheffer, R. J., Bakker, P. A. H. M., and Schippers, B. 1995. Biocontrol of Fusarium wilt of radish in commercial greenhouse trials by seed treatment with Pseudomonas fluorescens WCS374. Phytopathology 85:1301-1305.

25. Lemanceau, P., and Alabouvette, C. 1991. Biological control of Fusarium diseases by fluorescent Pseudomonas and non-pathogenic Fusarium. Crop Prot. 10:279-286.

26. Li, Q., Lawrence, C. B., Xing, H. Y., Babbitt, R. A., Bass, W. T., Maiti, I. B., and Everett, N. P. 2001. Enhanced disease resistance conferred by expression of an antimicrobial magainin analog in transgenic tobacco. Planta 212:635-639.

27. Lund, S. T., Stall, R. E., and Klee, H. J. 1998. Ethylene regulates the susceptible response to pathogen infection in tomato. Plant Cell 10:371382.

28. Mes, J. J., Weststeijn, E. A., Herlaar, F., Lambalk, J. J. M., Wijbrandi, J., Haring, M. A., and Cornelissen, B. J. C. 1999. Biological and molecular characterization of Fusarium oxysporum f. sp. lycopersici divides race 1 isolates into separate virulence groups. Phytopathology 89:156-160.

29. Montalbini, P., Buonaurio, R., and Kumar, N. N. U. 1995. Peroxidase activity and isoperoxidase pattern in tobacco leaves infected with tobacco necrosis virus and other viruses inducing necrotic and non-necrotic alterations. J. Phytopathol. 143:295-301.

30. Murashige, T., and Skoog, F. 1962. A revised medium for rapid growth and bioassays with tobacco cell cultures. Physiol. Plant 15:473 - 497.

31. Norman-Setterblad, C., Vidal, S., and Palva, E. T. 2000. Interacting sinal pathways control defense gene expression in Arabidopsis in response to cell wall-degrading enzymes from Erwinia carotovora. Mol. PlantMicrobe Interact. 13:430-438.

32. Pieterse, C. M. J., Van Wees, S. C. M., Hoffland, E., Van Pelt, J. A., and Van Loon, L. C. 1996. Systemic resistance in Arabidopsis induced by biocontrol bacteria is independent of salicylic acid accumulation and pathogenesis-related gene expression. Plant Cell 8:1225-1237.

33. Pirhonen, M., Heino, P., Helander, I., Harju, P., and Palva, E. T. 1988. Bacteriophage T4 resistant mutants of the plant pathogen Erwinia carotovora. Microb. Pathog. 4:359-367.

34. Ran, L. 2002. Suppression of bacterial wilt in Eucalyptus and bacterial speck in Arabidopsis by fluorescent Pseudomonas spp. strains: Conditions and mechanisms. Ph.D. thesis. Utrecht University, Utrecht, The Netherlands.

35. Reuber, T. L., Plotnikova, J. M., Dewdney, J., Rogers, E. E., Wood, W., and Ausubel, F. M. 1998. Correlation of defense gene induction defects with powdery mildew susceptibility in Arabidopsis enhanced disease susceptibility mutants. Plant J. 16:473-485.

36. Reuveni, R. 1995. Biochemical markers as tools for screening resistance against plant pathogens. Pages 21-45 in: Novel Approaches to Integrated Pest Management. R. Reuveni, ed. CRC Press, Boca Raton, FL.

37. Thomma, B. P. H. J., Eggermont, K., Penninckx, I. A. M. A., MauchMani, B., Vogelsang, R., Cammue, B. P. A., and Broekaert, W. F. 1998. Separate jasmonate-dependent and salicylate-dependent defense-response 
pathways in Arabidopsis are essential for resistance to distinct microbial pathogens. Proc. Natl. Acad. Sci. USA 95:15107-15111.

38. Thomma, B. P. H. J., Eggermont, K., Tierens, K. F. M.-J., and Broekaert, W. F. 1999. Requirement of functional ethylene-insensitive 2 gene for efficient resistance of Arabidopsis to infection by Botrytis cinerea. Plant Physiol. 121:1093-1101.

39. Thomma, B. P. H. J., Penninckx, I. A. M. A., Broekaert, W. F., and Cammue, B. P. A. 2001. The complexity of disease signaling in Arabidopsis. Curr. Opin. Immunol. 13:63-68.

40. Ton, J., Van Pelt, J. A., Van Loon, L. C., and Pieterse, C. M. J. 2002. Differential effectiveness of salicylate-dependent and jasmonate/ethylene- dependent induced resistance in Arabidopsis. Mol. Plant-Microbe Interact. 15:27-34

41. Van Peer, R., Niemann, G. J., and Schippers, B. 1991. Induced resistance and phytoalexin accumulation in biological control of Fusarium wilt of carnation by Pseudomonas sp. strain WCS417r. Phytopathology 81:728734.

42. Way, H. M., Kazan, K., Goulter, K. C., Birch, R. G., and Manners, J. M. 2000. Expression of the Shpx 2 peroxidase gene of Stylosanthes humilis in transgenic tobacco leads to enhanced resistance to Phytophthora parasitica pv. nicotianae and Cercospora nicotianae. Mol. Plant Pathol. $1: 223-232$. 